\title{
Laminopathies; Mutations on single gene and various human genetic diseases
}

\author{
So-mi Kang, Min-Ho Yoon \& Bum-Joon Park ${ }^{*}$ \\ Department of Molecular Biology, College of Natural Science, Pusan National University, Busan 46241, Korea
}

\begin{abstract}
Lamin A and its alternative splicing product Lamin C are the key intermediate filaments (IFs) of the inner nuclear membrane intermediate filament. Lamin $\mathrm{A} / \mathrm{C}$ forms the inner nuclear mesh with Lamin B and works as a frame with a nuclear shape. In addition to supporting the function of nucleus, nuclear lamins perform important roles such as holding the nuclear pore complex and chromatin. However, mutations on the Lamin A or Lamin B related proteins induce various types of human genetic disorders and diseases including premature aging syndromes, muscular dystrophy, lipodystrophy and neuropathy. In this review, we briefly overview the relevance of genetic mutations of Lamin A, human disorders and laminopathies. We also discuss a mouse model for genetic diseases. Finally, we describe the current treatment for laminopathies. [BMB Reports 2018; 51(7): 327-337]
\end{abstract}

\section{INTRODUCTION}

The main character of eukaryotes is the presence of separated genome containing nucleus from cytoplasm (1). Although there are many merits to the existing nucleus acting as a separated organelle (stable maintenance of genomic material and alternative use of genetic material), the morphology of the nucleus needs to be maintained and the materials should be transported across the nuclear membrane, which is continuous with the Endoplasmic Reticulum (ER; 2). To maintain the nuclear morphology and ensure resilience, the intermediate filament mesh in the inner nuclear membrane and the nuclear plasm can also co-evolve with eukaryotic cells. The core components of the nuclear intermediate filaments (IFs) are Lamin A, Lamin C, and Lamin B (3). These proteins are conserved from yeast to mammalian cells (4). However, these proteins do not seem to be part of the simple physical network

*Corresponding author. Tel: +82-51-510-2220; Fax: +82-51-5139258; E-mail: bjpark1219@pusan.ac.kr

https://doi.org/10.5483/BMBRep.2018.51.7.113

Received 25 April 2018

Keywords: EDMD, HGPS, Lamin A, Laminopathy, Nuclear membrane of the nuclear plasm. Lamin $\mathrm{A} / \mathrm{C}$ forms a network and is associated with Emerin and the nuclear pore complex $(5,6)$. Emerin is a linker between the Lamin A/C mesh and the cytoplasmic actin filament (7). Thus, this interaction may involve the localization of the nucleus in all cells and nuclear movement when cells migrate (8) A more interesting feature is the absence of Lamin $\mathrm{A} / \mathrm{C}$ expression in stem cells and neurons $(9,10)$; these types of cells only express Lamin B as a nuclear IF.

Due to the various functions of Lamin $\mathrm{A} / \mathrm{C}$, genetic mutations on Lamin $\mathrm{A} / \mathrm{C}$ induce a broad range of human genetic diseases (so called laminopathies; 11-14). The case of laminopathy is very unusual. In general, mutations on a single gene are involved in a single disease. For example, various types of genetic mutations on p53 are related to cancer or cancer-related pathogenesis (15). However, mutations on Lamin A/C can induce different diseases from premature aging to neuropathy.

In this paper, we discuss the physiological processing of Lamin $\mathrm{A} / \mathrm{C}$ and the relevance of mutations and laminopathies. We also describe the recent treatment of laminopathies.

\section{LAMIN A PROCESSING}

The LMNA gene is located on chromosome 1q21.2 loci and is composed of 12 exons (Fig. 1; 16). Exons 1-10 between Lamin $A$ and Lamin $C$ are identical (Fig. 1) and exons 11 and 12 are specific to Lamin A. Lamin C is produced by unique exon 11, which is transcribed by alternative splicing and translated into only 6 amino acids (VSGSRR; 17). Exon 12 on Lamin A possesses a CaaX motif (actual amino acid sequence is CSIM), which is at the end of Lamin A and the farnesylated motif (18). Lamin A is first produced as prelamin A containing the CaaX motif and maturates by protease-mediated cleavage $(17,18)$. Thus, matured Lamin A does not have a farnesylated CaaX motif. Zmspte24 has been suggested as the responsible protease for Lamin A maturation (19). Loss of Zmste24 also induces laminopathies (lipodystrophy and dermopathy; 20, 21). Thus, the correct processing of Lamin A is also important for maintaining a healthy cellular condition. The biological function of C-terminal farnesylation would be targeting of Lamin A to nuclear membrane. However, considering that only mature Lamin A mouse expression is indistinguishable 


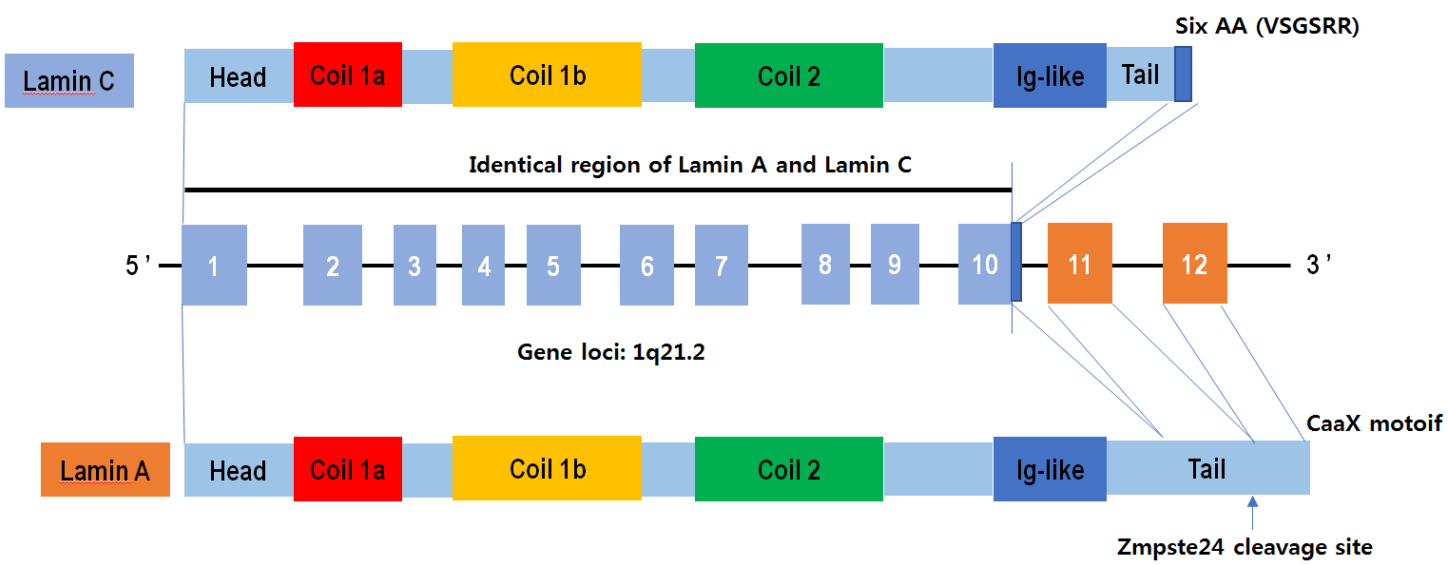

Fig. 1. Structure of LMNA gene. LMNA, encoding Lamin A/C is composed of 12 exons and the two produced proteins, Lamin $A$ and Lamin C. Exon 1-10 are commonly used for Lamin A and C proteins. However, exon 11 and 12 are only used by Lamin A. Since the end of exon 12 encodes CaaX motif (actually CSIM), only Lamin A is a target for farnesyl-transferase. In addition, the Zmpste24 protease target sequence is located in exon 11. Thus, Farnesylated Lamin A (prelamin A) is processed into mature Lamin A. Lamin C is produced by Exon 1-10 differentially from Lamin A. However, the final exon is differentially used from lamin by alternative splicing (dark blue box in middle panel). Consequently, the six C-terminal amino acids (VSGSRR; dark blue box) are uniquely derived from Lamin A. We also showed the structural domains of Lamin A/C.

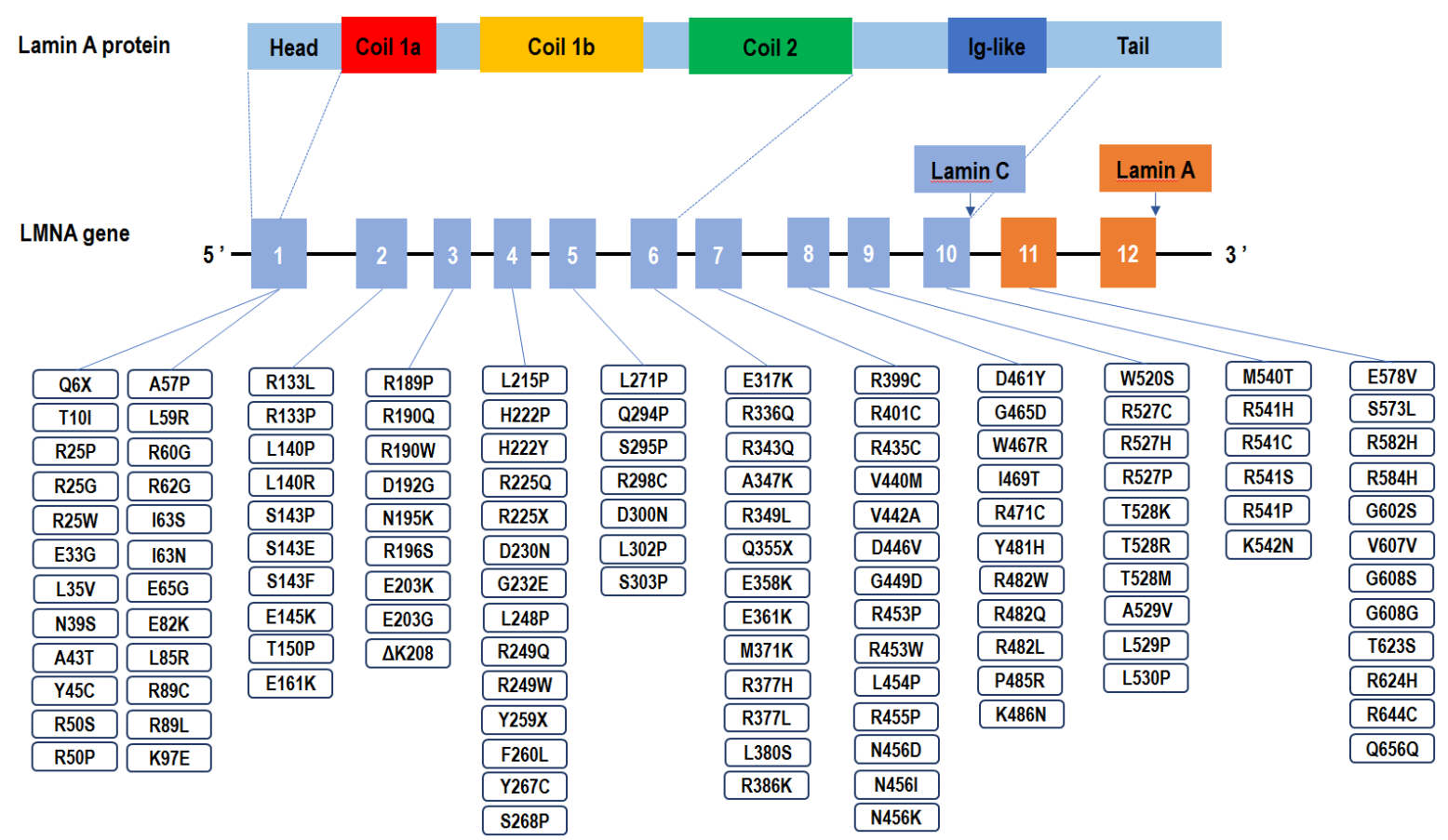

Fig. 2. Mutations on Lamin A. To date, more than 400s mutations have previously been found in Laminopathies. Mutations are widely distributed throughout the entire Lamin A gene. See table 1 for co-relationship between mutations and diseases.

from wild type mouse (22), it is unclear why Lamin A is expressed as prelamin A. This implies that matured Lamin A does not work as an attached form of the nuclear membrane.
In contrast, the binding of Lamin A (prelamin A) on the nuclear inner membrane may cause problems (laminopathies). The CaaX motif of Lamin B expressed differentially from Lamin A is 
not eliminated, and Lamin B is associated with the nuclear membrane (23). These results suggest that the primary nuclear IF is the Lamin B mesh. In fact, Lamin B is expressed in all types of cells, including stem cells and neurons. In addition, the rarity of laminopathies by Lamin B mutation also supports the possibility that Lamin B is a more essential IF than Lamin A.

\section{LAMINOPATHIES AND MUTATIONS}

As described previously, mutations on Lamin A or related proteins induce various types of human diseases. These diseases are divided into two large categories: primary laninopathies which are induced by mutations on Lamin A and secondary laminopathies which are caused by mutations on Lamin B (Lamin B1 and Lamin B2), prelamin processing proteins (such as Zmpste24) or lamin binding proteins (such as emerin). To date, more than 400 mutations in the Lamin A gene have been identified from patients. However, each mutation has a very wide range of phenotypes, and the genetic features vary such that in some cases function is gained, while in others function is lost. Fig. 2 and Table 1 show the mutations of Lamin A and the related diseases. The following section describes several mutations and their relevance to disease symptoms.

\section{MUSCULAR DYSTROPHY}

Many types of Lamin A mutations are related to muscular dystrophy. However, the tissues first affected differ from genetic mutations. Commonly called 'muscular dystrophy', the disease was first described in 1955 as Emery-Dreifuss muscular dystrophy (EDMD), which affects 1 in 100,000 births $(24,25)$. EDMD is divided into 3 groups as follows. The first group is referred to as autosomal dominant EDMD (AD-EDMD). A large portion of mutations on Lamin $A$ is included in this group. Thus, EDMD-related Lamin A mutations are generally gain-of-function mutations. Numerous mutations have been reported as EDMD-related mutations (Table 1). The second group is referred to as autosomal recessive EDMD (AR-EDMD). Some types of Lamin A mutations that make stop codon are represented in this group (26). The third group is referred to as X-linked EDMD (XL-EDMD). This type of mutation is caused by a loss of emerin, Lamin A binding protein $(25,27)$. Since the emerin gene is located on the X-chromosome, XL-EDMD

Table 1. Relevance of Lamin A mutations and human laminopathies

\begin{tabular}{|c|c|c|c|c|c|c|c|c|c|c|c|c|}
\hline \multicolumn{8}{|c|}{ Muscular dystrophy } & \multirow{2}{*}{$\begin{array}{c}\text { Neuropathy } \\
\text { CMT2B1 }\end{array}$} & \multicolumn{2}{|c|}{ Lipodystrophy } & \multicolumn{2}{|c|}{ Segmental progeroid } \\
\hline \multicolumn{2}{|c|}{ CDM1A } & \multicolumn{3}{|c|}{ EDMD } & \multirow{2}{*}{$\begin{array}{r}\text { MLF } \\
\text { A57P }\end{array}$} & \multirow{2}{*}{$\begin{array}{l}\text { MDC } \\
\text { N39S }\end{array}$} & \multirow{2}{*}{$\frac{\text { LGMD1B }}{\text { R25G }}$} & & \multirow{2}{*}{$\begin{array}{l}\text { FPLD2 } \\
\text { R25W }\end{array}$} & \multirow{2}{*}{$\frac{\text { MAD }}{\text { V440M }}$} & \multirow{2}{*}{$\begin{array}{l}\text { AWS } \\
\text { A57P }\end{array}$} & \multirow{2}{*}{$\begin{array}{l}\text { HGPS } \\
\text { T10I }\end{array}$} \\
\hline Q6X & E203K & Q6X & G232E & G449D & & & & R298C & & & & \\
\hline R25G & E203G & R25P & L248P & R453W & L59R & R50P & Y259X & & R60G & R471C & R133L & S143E \\
\hline R25W & L215P & R25G & R249Q & L454P & & R249W & E358K & & $\mathrm{R} 62 \mathrm{G}$ & R527C & L140R & S143F \\
\hline L59R & R225X & E33G & R249W & N456I & & L302P & $\mathrm{R} 377 \mathrm{H}$ & & $\Delta K 208$ & $\mathrm{R} 527 \mathrm{H}$ & D300N & E145K \\
\hline R60G & Y267C & L35V & F260L & N456K & & E358K & R377L & & D230N & A529V & Q656Q & R471C \\
\hline E82K & E317K & N39S & Y267C & D461Y & & L380S & R399C & & G456D & & & R527C \\
\hline L85R & A347K & A43T & S268P & W467R & & R453P & $\mathrm{Y} 481 \mathrm{H}$ & & R482W & & & T528M \\
\hline R89L & R349L & Y45C & L271P & I469T & & R455P & & & R482Q & & & M540T \\
\hline K97E & Q355X & R50S & Q294P & W520S & & N456D & & & R482L & & & $\mathrm{K} 542 \mathrm{~N}$ \\
\hline S143P & R399C & $163 S$ & S295P & R527P & & & & & P485R & & & E578V \\
\hline E161K & $\mathrm{R} 435 \mathrm{C}$ & $163 \mathrm{~N}$ & S303P & T528K & & & & & K486N & & & V607V \\
\hline R190W & R541C & E65G & R336Q & T528R & & & & & S573L & & & G608S \\
\hline D192G & R541S & R89C & R343Q & L529P & & & & & $\mathrm{R} 582 \mathrm{H}$ & & & G608G \\
\hline \multirow[t]{8}{*}{ N195K } & S573L & R133P & E358K & L530P & & & & & $\mathrm{R} 584 \mathrm{H}$ & & & T623S \\
\hline & $\mathrm{R} 644 \mathrm{C}$ & L140P & E361K & $\mathrm{R} 541 \mathrm{H}$ & & & & & & & & \\
\hline & & $\mathrm{T} 150 \mathrm{P}$ & M371K & R541S & & & & & & & & \\
\hline & & R189P & R377L & R541P & & & & & & & & \\
\hline & & R190Q & R386K & G602S & & & & & & & & \\
\hline & & R196S & R401C & $\mathrm{R} 624 \mathrm{H}$ & & & & & & & & \\
\hline & & $\mathrm{H} 222 \mathrm{P}$ & V442A & & & & & & & & & \\
\hline & & $\mathrm{H} 222 \mathrm{Y}$ & D446V & & & & & & & & & \\
\hline
\end{tabular}

CDM1A: Cardiomyopathy, dilated, 1A, EDMD: Emery-Dreifuss Muscular dystrophy, MLF: Malouf syndrome, MDC: Muscular dystrophy, congenital, LGMD1B: Muscular dystrophy, limb-gardle, type 1B, CMT1B1: Charcot-Marie-Tooth disease, type 2B1, FDLD2: Lipodystrophy, familial partial, 2, MAD: Mandibuloacral dysplasia lipodystrophy, AWS: Atypical Werner syndrome, HGPS: Hutchinson-Gilford progeria syndrome. 
affects males. Although XL-EDMD causes very severe muscle dystrophy, the emerin knockout mouse model shows a healthy condition with XL-EDMD (28). This demonstrates the genetic difference between human and mouse species.

EDMD primarily affects skeletal muscles, and is detected from teenage years $(26,29)$. The characteristic of EDMD is a slow, progressive wasting of skeletal muscles in the shoulder girdle and distal leg muscles. The histological features of the muscles of a person affected by EDMD are various muscle fiber sizes and the mislocalization of the cell nucleus (25-29). Cardiac muscle dystrophy is also observed in EDMD, which differs from dilated cardiomyopathy (CMD) in which skeletal muscles are not affected $(26,29)$. Thus, mutations causing EDMD seem to induce broader functional defects than CMD-related mutations. Although CDM is induced by other genes, 5 mutations on Lamin $A$ have been reported to be related to CMD (30). In addition, Lamin A mutations also induce Limb-girdle muscular dystrophy, type 1B, and Malouf syndrome (mutations A57P and L59RI, 31-34). Interestingly, A57P and L59R mutations are also found in atypical Werner syndrome (A57P) and CDM1A (L59R). The reason why identical mutations induce different phenotypes has yet to be found. Table 1 shows the relevance of Lamin A mutations and human laminopathies.

\section{Lipodystrophy}

The clinical feature of Lipodystrophy (LD) is the reduction or loss of subcutaneous adipose tissue (35). Loss of fat has been detected from childhood or early adulthood. Two categories of LD are caused by mutation on Lamin A or related proteins: Familial partial lipodystrophy type 2 (FPLD2) and Mandibuloacral dysplasia (MAD). The main areas of the body affected by AMD are the face, neck and truck. Loss of adipose tissue can cause insulin resistance, and subsequently diabetes. The lipodystrophy-related Lamin A mutations are listed in Table 1.

\section{Neuropathies}

Duplication or overexpression of Lamin B1 induces adult-onset autosomal dominant leukodystrophy (ADLD), which is slowly progressive $(36,37)$. Symptoms are therefore apparent in people in their 40s and 50s. On the other hand, Lamin A mutation (R298C) can induce Charcot-Marie-Tooth (CMT) disorder (autosomal recessive CMT2A). However, the reason why the overexpression of the Lamin B1 or Lamin A mutation induces neuropathies has not yet been addressed until now.

\section{Segmental progeroid diseases}

Although mutations on Lamin A induce various types of

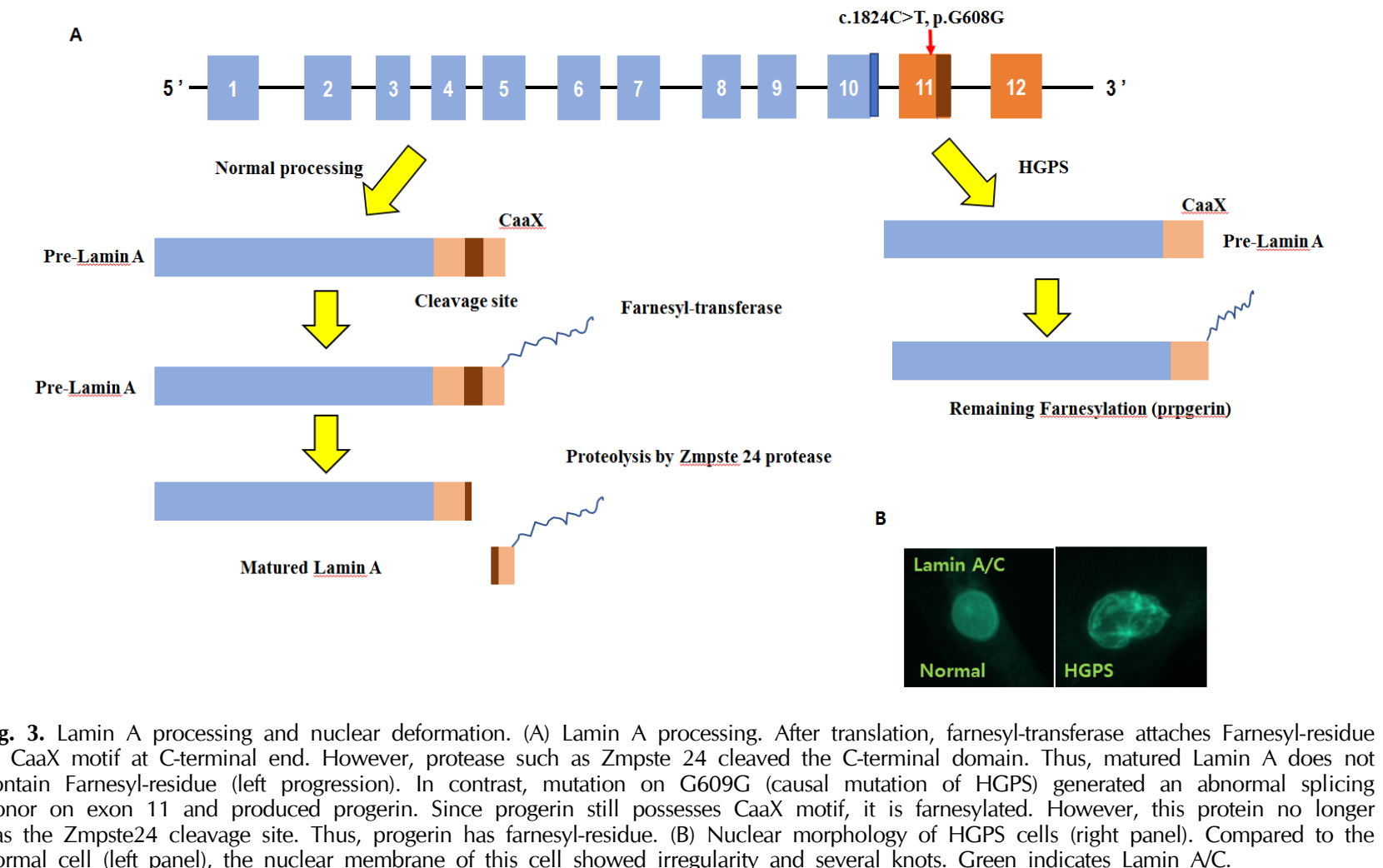

$.1824 C>$ T, p.G608G 
diseases, the most interesting feature is their promotion of premature aging. Since the aging process is believed to be generated by very complicated mechanisms, it is astonishing that a single mutation on Lamin A promotes the aging process.

Hutchinson-Gilford progeria syndrome (HGPS) is a well-known aging related disease (38). HGPS is a very rare genetic disorder ( 1 in 20,000,000), in which all aging related features are displayed at an early stage, except cancer and neuro-degenerative diseases (38-40). HGPS patients suffer from sarcopenia, lipodystrophy, diabetes, cataracts, and atherosclerosis (41). In general, patients die from cardiovascular complications in their early teenage years $(41,42)$. At least $90 \%$ of all HGPS cases are caused by a single base pair substitution at exon 11 of the Lamin A gene (c.1824C > T, p.G608G). Although this mutation does not change the amino acid, it generates a new splicing donor site (Fig. 2A). Thus, the product of mutation is 50 amino acid deleted (intra-deletion) abnormal Lamin A, so called progerin (Fig. 3A; 38). Since 50 amino acid sequences containing Zmpste24-cleavage sites are deleted, progerin is not processed by protease, and the farnesylated CaaX motif remains. Based on this, an attempt has previously been made to use the inhibitor of farnesyltransferase (lonafarnib) as a treatment for HGPS, although this treatment did not show a favorable outcome (43).

Since many clinical features of HGPS resemble the physiological aging process, many researchers have expressed interest in the molecular mechanism by which progerin promotes aging (44). In fact, in healthy people, progerin expression is detected and increases with the aging process (45). Also, the cellular characteristic of HGPS, nuclear blebbing, is detected in normally aged cells (Fig. 3B), supporting the belief that the aging process induced by HGPS is a phenocopy of the physiological aging process. In addition to progerin production, several mutations have been reported to be related to HGPS.

Among the secondary laminopathy, Zmpste24 deletion is also related to segmental progeroid syndrome, Restrictive Dermopathy (RD; 46). Usually, RD patients die within a few weeks of birth due to respiratory failure (47). However, the Zmpste24-/- mouse can live longer than 6 months, although it has a small body size and aging-related phenotypes. This difference raises a new question about how the mouse model can accurately show the disease-phenotype of humans, and further indicates the difference between human and mouse systems. Along with HGPS, Werner syndrome (WS) is another well-known premature aging disease (48). Since premature aging features are displayed after puberty, it is called the 'progeria of the adult'. Although clinical features are detected after puberty, WS shows all of the aging features, such as skin atrophy, ulcers, cataracts, type 2 diabetes mellitus, sarcoma, etc. $(49,50)$. Thus, WS is also believed to be a useful model for studying the physiological aging process with HGPS. Although it is a rare genetic disorder, the incidence of WS is unusually high in Japan (51). Causal mutation of WS is a loss of the WRN gene which encodes a DNA helicase, and is included in the RecQ4 family (48). Although about $80 \%$ of WS cases are caused by WRN mutation, the remaining $20 \%$ do not harbor the WRN mutation (atypical Werner syndrome: AWS; 52). Among the WS cases, a small portion (about 20\%) has mutations on Lamin A (Table 1). These features suggest that some types of Lamin A mutations can disrupt the function of WRN.

\section{MOUSE MODEL FOR LAMINOPATHIES}

Mouse models are widely used to understand the physiological and pathological mechanism of human genes. The appropriate mouse model is critical in drug development

Table 2. List of knockout mouse model of Lamin A or related proteins

\begin{tabular}{|c|c|c|c|c|c|}
\hline Abbreviation & Mutation & Homozygous Mouse Phenotype & $\begin{array}{l}\text { Heterozygous } \\
\text { Mouse Phenotype }\end{array}$ & Disease in Human & Ref \\
\hline $\mathrm{Lmna}^{-1-}$ & $\begin{array}{l}\text { Destruction of exons } 8 \text { to part of } 11 \\
\text { by using insertion of neomycin } \\
\text { resistant cassette }\end{array}$ & $\begin{array}{l}\text { Growth rate retardation. Body weight } \\
\text { loss. Emery-Dreifuss muscular } \\
\text { dystrophy (EDMD)-like phenotype }\end{array}$ & $\begin{array}{l}\text { No apparent } \\
\text { abnormalities }\end{array}$ & Not described & 53 \\
\hline Zmpste24 ${ }^{-1-}$ & $\begin{array}{l}\text { Deletion of exons } 2,3 \text { using } \\
\text { insertion of neomycin resistant } \\
\text { cassette }\end{array}$ & $\begin{array}{l}\text { Growth rate reduction. Pre-mature } \\
\text { aging }\end{array}$ & $\begin{array}{l}\text { No apparent } \\
\text { abnormalities }\end{array}$ & Not described & 54 \\
\hline $\operatorname{Lmna}^{\mathrm{GT}-1-}$ & $\begin{array}{l}\text { A promoter trap insertion into intron } \\
2 \text { resulting in a Lamin A-pgeo } \\
\text { fusion allele }\end{array}$ & $\begin{array}{l}\text { Cardiac hypertrophy causing } \\
\text { functional failure. Skeletal muscle } \\
\text { hypotrophy. }\end{array}$ & $\begin{array}{l}\text { No apparent } \\
\text { abnormalities }\end{array}$ & Not described & 55 \\
\hline $\mathrm{Lmna}^{\mathrm{LCO} / \mathrm{LCO}}$ & $\begin{array}{l}\text { Deletion of last } 150 \text { nucleotides of } \\
\text { exon } 11 \text { and deletion of intron } 11\end{array}$ & No apparent abnormalities & $\begin{array}{l}\text { No apparent } \\
\text { abnormalities }\end{array}$ & Not described & 56 \\
\hline $\mathrm{Lmna}^{\mathrm{LAO} / \mathrm{LAO}}$ & Mature Lamin A only & No apparent abnormalities & $\begin{array}{l}\text { No apparent } \\
\text { abnormalities }\end{array}$ & Not described & 22 \\
\hline $\mathrm{EDM}-1-$ & Emerin deletion & $\begin{array}{l}\text { No apparent abnormalities (slight } \\
\text { retardation on muscle regeneration) }\end{array}$ & $\begin{array}{l}\text { No apparent } \\
\text { abnormalities }\end{array}$ & EDMD & 57,58 \\
\hline
\end{tabular}


for human diseases. Consequently, many trials have been performed to create a mouse model for human laminopathies. The following section summarizes the laminopathy-related mouse models.

\section{Lamin A related knockout models (Table 2)}

To address the function of Lamin A, a Lamin A/C knockout mouse has been developed by the disruption of exon 8 to exon 11 (53). The elimination of all Lamin A and Lamin C shows growth retardation and loss of body weight. Collectively, Lamin A/C deletion induces EDMD-like phenotypes. However, heterozygous mice do not show any pathological features, indicating that a single copy of LMNA is sufficient for normal function performance. In contrast to total Lamin A/C deletion, the Lamin A deleted mouse model (generated by the deletion of exon 11) does not show apparent abnormalities (56). This result implies that, at least in the mouse model, Lamin A is dispensable for normal development when Lamin
$\mathrm{C}$ is normally expressed. In addition, a functional redundancy exists between Lamin A and Lamin C. The most interesting mouse model is $L m n a^{L A O / L A O}(22)$. While this mouse expresses only matured Lamin A, it is entirely normal with a nuclear defect in the fibroblast. This result leads to the same conclusion that, at least in the mouse system, prelamin $A$ is dispensable for normal development. In fact, if Lamin A does not contain exon11 and 12, it is almost identical to Lamin C. In contrast, Zmpste24 knockout mice display progeria-like phenotypes such as growth retardation, muscular dystrophy, and short life span (6-7 months). Thus, this model has been used for the study of HGPS. However, as described above, Zmpste24 deletion evokes RD.

From the knockout mouse model of Lamin A or Zmpste24, normal function of Lamin A is required for normal development and preventing progeria features.

An emerim knockout mouse model has also been developed to study $\operatorname{EDMD}(57,58)$. However, in contrast to human

Table 3. List of point mutant mouse model for laminopathies

\begin{tabular}{|c|c|c|c|c|c|}
\hline Abbreviation & Mutation & Homozygous Mouse Phenotype & Heterozygous Mouse Phenotype & Disease in Human & Ref \\
\hline$\Delta \mathrm{K} 32$ & $\begin{array}{l}\text { Deletion of } \mathrm{K} 32 \text { in } \\
\text { the } \mathrm{N} \text {-terminal } \\
\text { domain of lamins } \\
\text { A/C }\end{array}$ & $\begin{array}{l}\text { Kinked tail. Growth retardation. } \\
\text { Stagnation in weight gain. } \\
\text { Congenital muscular dystrophy. }\end{array}$ & Indistinguishable phenotype & $\begin{array}{l}\text { Congenital muscular } \\
\text { dystrophy. }\end{array}$ & 59 \\
\hline $\begin{array}{l}\text { Disheveled } \\
\text { hair and ear } \\
\text { (Dhe) }\end{array}$ & $\begin{array}{l}\text { Sponteneous L52R } \\
\text { mutation }\end{array}$ & $\begin{array}{l}\text { Defect in bone mineralization, and } \\
\text { low collagen expression causing } \\
\text { abnormal morphology of skull, jaws, } \\
\text { and ears. Low bone mineral density. }\end{array}$ & $\begin{array}{l}\text { Defect in bone mineralization, } \\
\text { and low collagen expression } \\
\text { causing abnormal } \\
\text { morphology of skull, jaws, } \\
\text { and ears. Low bone mineral } \\
\text { density. }\end{array}$ & Not described & 60 \\
\hline N195K & Missense mutaiton & $\begin{array}{l}\text { Weight loss. Shortened lifespan. } \\
\text { Dilated cardiomyopathy (DCM)-like } \\
\text { phenotype }\end{array}$ & Not described & $\begin{array}{l}\text { Dilated cardiomyopathy } \\
\text { (DCM) }\end{array}$ & 61 \\
\hline $\mathrm{H} 222 \mathrm{P}$ & Missense mutaiton & $\begin{array}{l}\text { Indistinguishable phenotype during } \\
\text { sexual maturity stage. Weight loss } \\
\text { and reduced growth rate in adult } \\
\text { stages. Cardiac dysfunction. Skeletal } \\
\text { muscle dystrophy. Lipodystrophy. }\end{array}$ & Indistinguishable phenotype & Not described & 62 \\
\hline M371K & Missense mutaiton & $\begin{array}{l}\text { Cardiac pathology (IOncreased } \\
\text { cytoplasmic eosinophilia of } \\
\text { cardiomyocytes, focal edema, } \\
\text { fragmented cardiomyofibrils and } \\
\text { pyknotic-appearing nuclei) }\end{array}$ & Not described & Not described & 63 \\
\hline R482Q & Missense mutaiton & Not described & $\begin{array}{l}\text { Familial partial lipodystrophy } \\
\text { of the Dunnigan type (FPLD2) }\end{array}$ & $\begin{array}{l}\text { Familial partial } \\
\text { lipodystrophy of the } \\
\text { Dunnigan type (FPLD2). } \\
\text { No homozygous patients } \\
\text { have been identified. }\end{array}$ & 64 \\
\hline L530P & Missense mutaiton & $\begin{array}{l}\text { Progeroid phenotype. Growth } \\
\text { retardation. }\end{array}$ & Indistinguishable phenotype & $\begin{array}{l}\text { Autosomal dominant form of } \\
\text { Emery Dreifuss muscular } \\
\text { dystrophy (AD-EDMD) }\end{array}$ & 65 \\
\hline G608G & $\begin{array}{l}\text { Mouse G606G base } \\
\text { change using BAC } \\
\text { system }\end{array}$ & $\begin{array}{l}\text { Progeroid phenotype. Growth } \\
\text { retardation. }\end{array}$ & Indistinguishable phenotype & $\begin{array}{l}\text { Hutchinson-Gilford progeria } \\
\text { syndrome (HGPS) }\end{array}$ & 66 \\
\hline G609G & $\begin{array}{l}\text { Insertion of G609G } \\
\text { in exon } 11\end{array}$ & $\begin{array}{l}\text { Hutchinson-Gilford progeria } \\
\text { syndrome (HGPS) }\end{array}$ & $\begin{array}{l}\text { Hutchinson-Gilford progeria } \\
\text { syndrome (HGPS) }\end{array}$ & $\begin{array}{l}\text { Hutchinson-Gilford progeria } \\
\text { syndrome (HGPS) }\end{array}$ & 67 \\
\hline
\end{tabular}


EDMD, complete emerin knockout does not produce EDMD phenotype. This result suggests that the regulation mechanism of Lamin A or nuclear IF between human and mouse significantly differs.

\section{Lamin A Mutant knock-in mouse model (Table 3)}

Since EDMD or lipodystrophy is an autosomal dominant pattern, to mimic these features, several types of transgenic mouse models have been proposed (59-67). Curiously, AD-EDMD related mutations do not induce the EDMD phenotype in the knock-in mouse model. For example, Lmnat ${ }^{\text {wt/H222P }}$ mice show a phenotype undisguisable from wild type mice (62), even though this mutation induces AD-EDMD. Instead, Lmna ${ }^{H 222 P / H 222 P}$ mice (homozygous mice) display EDMD phenotypes such as muscle dystrophy and lipodystrophy. We can find a similar pattern in other types of mouse model (Table 3). These differences strongly suggest a fairly significant difference between human and mouse systems.

Among the various knock-in mouse models, the $\mathrm{Lmna}^{\mathrm{C} 609 \mathrm{C}}$ model has recently been intensively studied because it closely copies the human HGPS (67). Although this model shows the same limitation, $L m n a^{\mathrm{C} 609 \mathrm{G} / \mathrm{C} 609 \mathrm{G}}$ also shows very similar HGPS features such as obvious growth retardation, cardiovascular defects, and very short life span. Thus, using this model, intensive screening and development of new drugs for HGPS are currently being carried.

In addition to the knock-in mouse model, Lamin B1 mouse models have been generated (Table 4) since easily eliminated Lamin B1 induces an embryonic lethal phenotype (or neonatal lethal; 68). In contrast, the overexpression of Lamin B1 induces ADLD, which is consistent with human disease features (69).

\section{CURRENT TREATMENT OF LAMINOPATHIES}

Until now, an appropriate treatment for the fundamental pathogenic mechanism of laminopathies has not been suggested. Today, treatment for laminopathies is limited to relieving symptoms. Corrective surgery can be used for distorted body shape in EDMD (70) and coronary artery bypass surgery can be performed for HGPS (71). However, none of these treatments can cure the roots of these diseases.

For EDMD, the partial effect of rapamycin has been reported in a EDMD mouse model $(72,73)$. However, long term treatment of rapamycin can induce side effects such as lung toxicity, insulin resistance, and cataract. Thus, rapamycin is not an appropriate drug for EDMD.

Since farnesyl-residue is retained in progerin, lonafarnib (an inhibitor of farnesyl-transferase) has been used in the treatment of HGPS patients (74). Indeed, lonafarnib showed a favorable effect on nuclear morphology in a cell experiment (75). In addition, this chemical improved the disease phenotype in the Zmste24-/- mouse model (76). However, a phase II clinical trial with HGPS patients did not show any therapeutic effect $(43,77)$. Since lonafarnib has been developed as an anti-cancer drug, it is toxic to normal cells, rendering long-term treatmentimpossible. Indeed, long term treatment of lonafarnib induces a donut-shaped cell nucleus and defects in cell division (78). Considering the above, the treatment of lonafarnib for HGPS is not reasonable.

The co-treatment of lonafarnib and rapamycin has recently been suggested, and a clinical trial is on-going by the Progeria Research Foundation (43). However, as described above, the lonafarnib and rapamycin chemicals are not suitable for long-term treatment and they cannot correct the basic mechanism of HGSP. Antisense oligonucleotide has also been proposed for treatment of HGPS (79), and has been shown to extend the life span of a HGPS mouse model ( $L m n a^{\mathrm{C} 609 \mathrm{C} / \mathrm{G} 609 \mathrm{G}}$ ) by about 4 weeks (average life span: 16 weeks vs. 20 weeks; 80). However, until now, it has been impossible to deliver the antisense oligonucleotide to all tissues. Other approaches are currently being made to find a drug for HGPS, for example by generating a new drug for HGPS based on a novel pathological mechanism. The previous pathogenic mechanism is the accumulation of pre-lamin A and retention of farnesyl-residue. However, while Zmspte24-/- induces RD, it does not induce HGPS. This implies that progerin, a causal product of HGPS, has a unique pathological mechanism. A recent study suggested that progerin shows a very strong binding affinity with wild type Lamin A and disrupts the nuclear membrane

Table 4. Mouse model of Lamin B mutations

\begin{tabular}{|c|c|c|c|c|c|}
\hline Abbreviation & Mutation & Homozygous Mouse Phenotype & $\begin{array}{l}\text { Heterozygous } \\
\text { Mouse Phenotype }\end{array}$ & Disease in Human & Ref \\
\hline Lamin B1 $\Delta / \Delta$ & $\begin{array}{l}\text { Portion of the rod domain and the } \\
\text { entire carboxyl-terminal domain } \\
\text { are replaced by gene trap } \\
\text { insertion }\end{array}$ & $\begin{array}{l}\text { Embryonic lethal, reduced embryo size and } \\
\text { shows abnormal embryo shape. Abnormal } \\
\text { lung development and bone ossification } \\
\text { in embryo development }\end{array}$ & $\begin{array}{l}\text { No apparent } \\
\text { abnormalities }\end{array}$ & Not described & 68 \\
\hline Lamin B1 BAC & $\begin{array}{l}\text { Overexpresion of Lamin B1 using } \\
\text { BAC insertion }\end{array}$ & $\begin{array}{l}\text { Autosomal-dominant leukodystrophy } \\
\text { (ADLD). Aberrant myelin formation, } \\
\text { axonal degeneration, and demyelination } \\
\text { causing cognitive and motor deficits. }\end{array}$ & $\begin{array}{l}\text { No apparent } \\
\text { abnormalities }\end{array}$ & $\begin{array}{l}\text { Autosomal-domina } \\
\text { nt leukodystrophy } \\
\text { (ADLD) }\end{array}$ & 69 \\
\hline
\end{tabular}




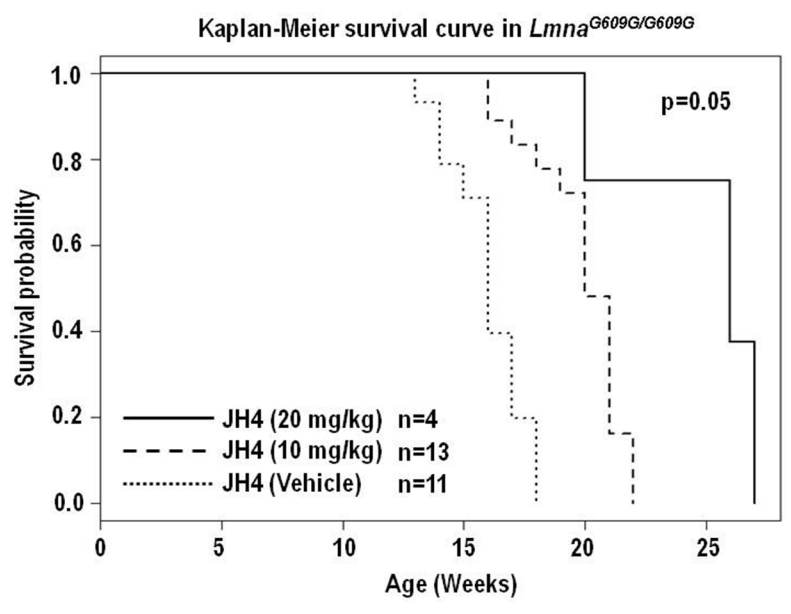

Fig. 4. Life span of HGPS mouse model. Lmna G609G/G609G mice showed a very short life span (average life span is 16 weeks). Treatment of Lamin A-progerin binding inhibitor $(\mathrm{JH} 4)$ could extend life span up to 27 weeks. Chemicals were injected via intraperitoneal injection (i.p) with the indicated concentration (twice/week).

structure (45). A new progerin-Lamin A binding inhibitor (small chemical) has thus been proposed as a candidate drug for HGPS (45). The treatment of HGPS with this chemical can extend the life span provided the antisense oligonucleotide treatment is carried out using the $L m n a^{\mathrm{C} 609 \mathrm{C} / \mathrm{C} 609 \mathrm{C}}$ mouse model. Moreover, an increase of the chemical dose can extend the life span up to 27 weeks (Fig. 4; 45). Thus, this chemical could be a strong candidate drug for HGPS.

\section{CONCLUSION}

In this paper, we described laminopathies and mutations. Mutations on Lamin A or related genes induce a very diverse spectrum of human diseases ranging from muscular dystrophy to progeria. In addition, we found that some mouse models are inappropriately matched for human disease due to the different systems or different roles of Lamin A among organisms. It would thus be beneficial to understand why and how Lamin A mutations on different sites or even in the same site generate different human pathologies. Until now, no clear answer on this has been presented.

Lamin A is normally processed through a multi-step process as follows. Prelamin A develops into mature Lamin A and forms the dimer. The dimerized Lamin A then develops into tetramerization by dimer-dimer interaction. Tetramerized Lamin A then forms the mesh network with Lamin A or with other linker proteins such as emerin. Therefore, each residue of Lamin A is important for each step. However, we did not know the exact mechanism of Lamin A mesh processing. In addition, Lamin A tends to hold the chromosome to retain chromosomal territory. Thus, if we know the exact molecular mechanism of Lamin A processing and function, we could develop more effective drugs for laminopathies.

Laminopathies are a group of very rare genetic disorders. However, they are involved in various types of diseases. As shown above, the progerin-mediated aging process is believed to be useful for understanding the general aging process. Similarly, laminopathy-related EDMD is possibly related to aging-induced sarcopenia or cardiac diseases. Thus, understating of the molecular mechanism of laminopathies would be useful for the investigation of other chronic diseases including diabetes and aging.

\section{ACKNOWLEDGEMENTS}

This work was supported by a 2-Year Research Grant from Pusan National University (2017-2019).

\section{CONFLICTS OF INTEREST}

The authors have no conflicting interests.

\section{REFERENCES}

1. McKenna T, Baek JH and Eriksson M (2013) Laminopathies. Genetic Disorders chapter 2, 28-64

2. Cronshaw JM, Kruchinsky AN, Zhang W, Chait BT and Matunis MJ (2002) Proteomic analysis of the mammalian nuclear pore complex. J Cell Biol 158, 915-927

3. Aebi U, Cohn J, Buhle L and Gerace L (1986) The nuclear lamina is a meshwork of intermediate-type filaments. Nature 323, 560-564

4. Gruenbaum Y and Foisner R (2015) Lamins: Nuclear intermediate filament proteins with fundamental functions in nuclear mechanics and genome regulation. Annu Rev Biochem 84, 131-164

5. Clements L, Manilal S, Love DR and Morris GE (2000) Direct interaction between emerin and lamin A. Biochem Biophys Res Commun 267, 709-714

6. Zastrow MS, Vlcek S and Wilson KL (2004) Proteins that bind A-type lamins: integrating isolated clues. J Cell Sci 117, 979-987

7. Salpingidou G, Smertenko A, Hausmanowa-Petrucewicz I, Hussey PJ and Hutchison CJ (2007) A novel role for the nuclear membrane protein emerin in association of the centrosome to the outer nuclear membrane. J Cell Biol $178,897-904$

8. Chang W, Folker ES, Worman HJ and Gundersen GG (2013) Emerin organizes actin flow for nuclear movement and centrosome orientation in migrating fibroblasts. Mol Biol Cell 24, 3869-3880

9. Constantinescu D, Gray HL, Sammak PJ, Schatten GP and Csoka AB (2006) Lamin $A / C$ expression is a marker of mouse and human embryonic stem cell differentiation. Stem Cells 24, 177-185

10. Röber RA, Weber K and Osborn M (1989) Differential timing of nuclear lamin $\mathrm{A} / \mathrm{C}$ expression in the various organs of the mouse embryo and the young animal: a 
developmental study. Development 105, 365-378

11. Briand $\mathrm{N}$ and Collas $\mathrm{P}$ (2018) Laminopathy-causing lamin A mutations reconfigure lamina-associated domains and local spatial chromatin conformation. Nucleus 9, 216-226

12. Chojnowski A, Ong PF and Dreesen O (2015) Nuclear lamina remodeling and its implications for human disease. Cell Tissue Res 360, 621-631

13. Worman HJ (2012) Nuclear lamins and laminopathies. J Pathol 226, 316-325

14. Ben Yaou R, Muchir A, Arimura T et al (2005) Genetics of laminopathies. Novartis Found Symp 264, 81-90

15. Hollstein M, Sidransky D, Vogelstein B and Harris CC (1991) p53 mutations in human cancers. Science 253, 49-53

16. Fisher D, Chaudhary N (1986) cDNA sequencing of nuclear lamins $A$ and $C$ reveals primary and secondary structural homology to intermediate filament proteins. Proc Ntl Acad Sci U S A 83, 6450-6454

17. Lin F, Worman HJ (1993) Structural organization of the human gene encoding nuclear lamin $\mathrm{A}$ and nuclear lamin C. J Biol Chem 268, 16321-16326

18. Barrowman J, Hamblet C, Geoge CM and Michaelis S (2008) Analysis of prelamin A biogenesis reveals the nucleus to be a CaaX processing compartment. Mol Biol Cell 19, 5398-5408

19. Barrowman J, Hamblet C, Kane MS and Michaelis S (2012) Requirements for efficient proteolytic cleavage of prelamin A by ZMPSTE24. PLoS One 7, e32120

20. Landires I, Pascale JM and Motta J (2007) The position of the mutation within the LMNA gene determines the type and extent of tissue involvement in laminopathies. Clin Genet 71, 592-593

21. Broers JLV, Ramaekers FCS, Bonne G, Yaou RB and Hutchison CJ (2006) Nuclear lamins: laminopathies and their role in premature ageing. Physiol Rev 86, 967-1008

22. Coffinier C, Jung HJ, Li Z et al (2010) Direct synthesis of lamin A, bypassing prelamin a processing, causes misshapen nuclei in fibroblasts but no detectable pathology in mice. J Biol Chem 285, 20818-20826

23. Kitten GT and Nigg EA (1991) The CaaX motif is required for isoprenylation, carboxyl methylation, and nuclear membrane association of lamin B2. J Cell Biol 113, 13-23

24. Emery AE and Dreifuss FE (1966) Unusual type of benign x-linked muscular dystrophy. J Neurol Neurosurg Psychiatry 29, 338-342

25. Muchir A and Worman HJ (2007) Emery-Dreifuss muscular dystrophy. Curr Neurol Neurosci Rep 7, 78-83

26. Bonne G, Mercuri E, Muchir A et al (2000) Clinical and molecular genetic spectrum of autosomal dominant Emery-Dreifuss muscular dystrophy due to mutations of the lamin A/C gene. Ann Neurol 48, 170-180

27. Helbling-Leclerc A, Bonne G and Schwartz K (2002) Emery-Dreifuss muscular dystrophy. Eur J Hum Genet 10, 157-161

28. Stewart CL, Kozlov S, Fong LG and Young SG (2007) Mouse models of the laminopathies. Exp Cell Res 313, 2144-2156

29. Canki-Klain N, Récan D, Milicić D et al (2000) Clinical variability and molecular diagnosis in a four-generation family with X-linked Emery-Dreifuss muscular dystrophy.
Croat Med J 41, 389-395

30. Fatkin D, MacRae C, Sasaki T et al (1999) Missense mutations in the rod domain of the lamin A/C gene as causes of dilated cardiomyopathy and conduction-system disease. N Engl J Med 341, 1715-1724

31. Muchir A, Bonne G, van der Kooi AJ et al (2000) Identification of mutations in the gene encoding lamins $\mathrm{A} / \mathrm{C}$ in autosomal dominant limb girdle muscular dystrophy with atrioventricular conduction disturbances. Hum Mol Genet 9, 1453-1459

32. Yuan WL, Huang CY, Wang JF et al (2009) R25G mutation in exon 1 of LMNA gene is associated with dilated cardiomyopathy and limb-girdle muscular dystrophy 1B. Chin Med J 122, 2840-2845

33. McPherson E, Turner L, Zador I, Reynolds K, Macgregor D and Giampietro PF (2009) Ovarian failure and dilated cardiomyopathy due to a novel lamin mutation. Am J Med Genet 149A, 567-572

34. Garg A, Subramanyam L, Agarwal AK et al (2009) Atypical progeroid syndrome due to heterozygous missense LMNA mutations. J Clin Endocrinol Metab 94, 4971-1983

35. Shackleton S, Lloyd DJ, Jackson SN et al (2000) LMNA, encoding lamin $\mathrm{A} / \mathrm{C}$, is mutated in partial lipodystrophy. Nat Genet 24, 153-156

36. Padiath QS, Saigoh K, Schiffmann R et al (2006) Lamin B1 duplications cause autosomal dominant leukodystrophy. Nat Genet 38, 1114-1123

37. Schuster J, Sundblom J, Thuresson AC et al (2011) Genomic duplications mediate overexpression of lamin B1 in adult-onset autosomal dominant leukodystrophy with autonomic symptoms. Neurogenetics 12, 65-72

38. Eriksson M, Brown WT, Gordon LB et al (2003) Recurrent de novo point mutations in lamin A cause HutchinsonGilford progeria syndrome. Nature 423, 293-298

39. Rodríguez Jl, Pérez-Alonso $P$, Funes $R$ and PérezRodríguez J (1999) Lethal neonatal Hutchinson-Gilford progeria syndrome. Am J Med Genet 82, 242-248

40. Gillar PJ, Kaye Cl and McCourt JW (1991) Progressive early dermatologic changes in Hutchinson-Gilford progeria syndrome. Pediatr Dermatol 8, 199-206

41. Merideth MA, Gordon LB, Clauss S et al (2008) Phenotype and course of Hutchinson-Gilford progeria syndrome. N Engl J Med 358, 592-604

42. Salamat M, Dhar PK, Neagu DL and Lyon JB (2010) Aortic calcification in a patient with Hutchinson-Gilford progeria syndrome. Pediatr Cardiol 31, 925-926

43. Gordon LB, Kleinman ME, Massaro J et al (2016) Clinical trial of the protein farnesylation inhibitors Lonafarnib, Pravastatin, and Zoledronic Acid in children with Hutchinson-Gilford progeria syndrome. Circulation 134, 114-125

44. Dechat T, Shimi T, Adam SA et al (2007) Alterations in mitosis and cell cycle progression caused by a mutant lamin A known to accelerate human aging. Proc Natl Acad Sci U S A 104, 4955-4960

45. Lee SJ, Jung YS, Yoon MH et al (2016) Interruption of progerin-lamin A/C binding ameliorates Hutchinson-Gilford progeria syndrome phenotype. J Clin Invest 126, 3879-3893 
46. Smigiel R, Jakubial A, Esteves-Vieira V et al (2010) Novel frameshifting mutations of the ZMPSTE24 gene in two siblings affected with restrictive dermopathy and review of the mutations described in the literature. Am J Med Genet 152A, 447-452

47. Mok Q, Curley R, Tolmie J and Marsden R (1990) Restrictive dermopathy: a report of three cases. J Met Genet 27, 315-319

48. Yu CE, Oshima J, Fu YH et al (1996) Positional cloning of the Werner's syndrome gene. Science 272, 258-262

49. Hisama FM, Lessel D, Leistritz D et al (2011) Coronary artery disease in a Werner syndrome-like form of progeria characterized by low levels of progerin, a splice variant of lamin A. Am J Med Genet 155A, 3002-3006

50. Hisama FM, Kubisch C, Martin GM and Oshima J (2012) Clinical utility gene card for: Werner syndrome. Eur J Hum Genet 20, 1-3

51. Goto M, Horiuchi $Y$, Tanimoto $K$, Ishii $T$ and Nakashima H (1978) Werner's syndrome: analysis of 15 cases with a review of the Japanese literature. J Am Geriatr Soc 26, 341-347

52. Chen L, Lee L, Kudlow BA et al (2003) LMNA mutations in atypical Werner's syndrome. Lancet 362, 440-445

53. Sullivan $T$, Escalante-Alcalde D, Bhatt $H$ et al (1999) Loss of A-type lamin expression compromise nuclear envelope integrity leading to muscular dystrophy. J Cell Biol 147, 913-920

54. Pendás AM, Zhou Z, Candiñanos J et al (2002) Defective prelamin A processing and muscular and adipocyte alterations in Zmpste24 metalloproteinase-deficient mice. Nat Genet 31, 94-99

55. Kubben N, Voncken JW, Konings G et al (2011) Post-natal myogenic and adipogenic developmental: defects and metabolic impairment upon loss of A-type lamins. Nucleus 2, 195-207

56. Fong LG, Ng JK, Lammerding J et al (2006) Prelamin A and lamin $A$ appear to be dispensable in the nuclear lamina. J Clin Invest 116, 743-752

57. Melcon G, Kozlov S, Cutler DA et al (2006) Loss of emerin at the nuclear envelope disrupts the Rb1/E2F and Myo D pathways during muscle regeneration. Hum Mol Genet 15, 637-651

58. Ozawa R, Hayashi YK, Ogawa M et al (2006) Emerin-lacking mice show minimal motor and cardiac dysfunctions with nuclear-associated vacuoles. Am J Pathol 168, 907-917

59. Pilat U, Dechat T, Bertrand AT et al (2013) The muscle dystrophy-causing $\Delta \mathrm{K} 32$ lamin $\mathrm{A} / \mathrm{C}$ mutant does not impair the functions of the nucleoplasmic lamin A/C-LAP2 $\alpha$ complex in mice. J Cell Sci 126, 1753-1762

60. Odgren PR, Pratt CH, Mackay CA et al (2010) Disheveled hair and ear (Dhe), a spontaneous mouse Lmna mutation modeling human laminopathies. PLoS One 5, e9959

61. Mounkes LC, Kozlov SV, Rottman JN and Stewart CL (2005) Expression of an LMNA-N195K variant of A-type lamins results in cardiac conduction defects and death in mice. Hum Mol Genet 14, 2167-2180

62. Arimura T, Helbling-Leclerc A, Massart C et al (2005) Mouse model carrying H222P-Lmna mutation develops muscular dystrophy and dilated cardiomyopathy similar to human striated muscle laminopathies. Hum Mol Genet $14,155-169$

63. Wang Y, Herron AJ and Worman HJ (2006) Pathology and nuclear abnormalities in hearts of transgenic mice expressing M371K lamin A encoded by an LMNA mutation causing Emery-Dreifuss muscular dystrophy. Hum Mol Genet 15, 2479-2489

64. Wojtanik KM, Edgemon K, Viswanadha S et al (2009) The role of LMNA in adipose: a novel mouse model of lipodystrophy based on the Dunnigan-type familial partial lipodystrophy mutation. J Lipid Res 50, 1068-1079

65. Mounkes LC, Kozlov S, Hernandez L, Sullivan T and Stewart CL (2003) A progeroid syndrome in mice is caused by defects in A-type lamins. Nature 423, 298-301

66. Varga R, Eriksson M, Erdos MR et al (2006) Progressive vascular smooth muscle cell defects in a mouse model of Hutchinson-Gilford progeria syndrome. Proc Natl Acad Sci U S A 103, 3250-3255

67. Osorio FG, Navarro CL, Cadiñanos J et al (2011) Splicing-directed therapy in a new mouse model of human accelerated aging. Sci Transl Med 3, 106ra107

68. Vergnes L, Péterfy M, Bergo MO, Young SG and Reue K (2004) Lamin B1 is required for mouse development and nuclear integrity. Proc Natl Acad Sci U S A 101, 10428-10433

69. Heng MY, Lin ST, Verret L et al (2013) Lamin B1 mediates cell-autonomous neuropathology in a leukodystrophy mouse model. J Clin Invest 123, 2719-2729

70. Ambrosi P, Mouly-Bandini A, Attarian S and Habib G (2009) Heart transplantation in 7 patients form a single family with limb-girdle muscular dystrophy caused by lamin AVC mutation. Int J Cardiol 137, e75-76

71. Dyck JD, David TE, Burke B, Webb GD, Henderson MA and Fowler RS (1987) Management of coronary artery disease in Hutchinson-Gilford syndrome. J Pediatr 111, 407-410

72. Ramos FJ, Chen SC, Garelick MG et al (2012) Rapamycin reverses elevated mTORC1 signaling in lamin A/C-deficient mice, rescue cardiac and skeletal muscle function, and extends survival. Sci Transl Med 4, 144ra103

73. Choi JC, Muchir A, Wu W and Iwata S (2012) Temsirolimus activates autophagy and ameliorates cardiomyopathy caused by lamin A/C mutation. Sci Transl Med 4, 144ra102

74. Kieran MW, Gordon L and Kleinman M (2007) New approaches to progeria. Pediatrics 120, 834-841

75. Capell B, Erdos M, Medigan J and Fiordalisi J (2005) Inhibiting farnesylation of progerin prevents the characteristic nuclear blebbing of Hutchinson-Gilford progeria syndrome. Pro Natl Acad Sci U S A 102, 12879-12884

76. Fong L, Frost D, Meta M, Qiao X and Yang S (2006) A protein farnesyltransferase inhibitor ameliorates disease in a mouse model of progeria. Science 311, 1621-1623

77. Gordon LB, Kleinman ME, Miller DT et al (2012) Clinical trial of a farnesyltransferase inhibitor in children with Hutchinson-Gilford progeria syndrome. Proc Natl Acad Sci USA 109, 16666-16671

78. Verstraeten VL, Peckham LA, Olive M et al (2011) Protein 
farnesylation inhibitors cause donut-shaped cell nuclei attributable to a centrosome separation defect. Proc Natl Acad Sci U S A 108, 4997-5002

79. Scaffidi P (2006) Lamin A-dependent nuclear defects in human aging. Science 312, 1059-1063

80. Osorio FG, Navarro CL, Cadinanos J et al (2011) Splicing-directed therapy in a new mouse model of human accelerated aging. Sci Transl Med 3, 106ra107 